Discussion Paper No. 578

\author{
WHY IS THERE DISCRIMINATION \\ AGAINST THE ELDERLY? \\ EXPERIMENTAL AND EMPIRICAL ANALYSES \\ FOR THE RENTAL HOUSING MARKET IN JAPAN
}

Masayuki Nakagawa

March 2003

The Institute of Social and Economic Research

Osaka University

6-1 Mihogaoka, Ibaraki, Osaka 567-0047, Japan 


\title{
Why Is There Discrimination Against the Elderly?* \\ Experimental and Empirical Analyses for the Rental Housing Market in Japan
}

\section{Masayuki Nakagawa**}

\begin{abstract}
Nakagawa(2001) and Nakagawa(2002) applies a fair housing audit technique to age discrimination in Japanese rental housing market, using data from the 2001 Osaka Audits. However, the experimental design of the study had some problems to be improved, e.g. lacked generality. This paper reports the outcome of a new fair housing audit (the 2002 Osaka Audits), in which improvements were added for these problems, and analyzes the existence of discrimination against the elderly as a whole and a variety of causes of age discrimination, using a broader range of tests of hypotheses.

The results obtained can be summarized as follows: housing discrimination against elderly home-seekers was observed on a statistically significant level. It was also suggested that the risk of the elderly's future income changing, the risk of fire caused by their negligence, the risk of their tenancy period becoming too long, and their preference for location of housing, as well as young people's preference for neighborhoods of young inhabitants, affected housing discrimination against elderly home-seekers. Finally, it was found that the patterns of restrictions on renting houses to the elderly differed according to their family structure and age.
\end{abstract}

\footnotetext{
* The author would like to express his gratitude to Professor Fumio Ohtake at Osaka University, who gave valuable comments received when writing this paper. The author also wants to thank Professor Kiyohiko Nishimura at the University of Tokyo and other people who took part in the Housing Economy Study Group for their useful suggestions. This work has been supported by a grant-in-aid for Category (C) fundamental studies from the Ministry of Education, Culture, Sports, Science and Technology's subsidy budget for scientific research (No. 13630054).

**Associate Professor, Institute of Social and Economic Research, Osaka University, Ibaraki, 567-0047, Japan. E-mail: nakagawa@iser.osaka-u.ac.jp
} 


\section{Introduction}

It is said that the elderly are given discriminatory treatment in the rental housing market in Japan, and the "Act for Stable Living of the Elderly" was passed in 2001 that contains many policies for improving elderly's housing level, e.g. creating a rent guarantee system and improving the provision of information on housing available for elderly tenants. Nakagawa (2001) and Nakagawa (2002) analyzed the situation of age discrimination using the audit study technique that has developed in the U.S. to detect racial discrimination. More specifically, the author conducted in 2001 a fair housing audit in which the existence and causes of discrimination was tested by pairs of auditors, who had the same attributes except that one of the pair was an elderly auditor and the other was a young auditor, visit the same real estate agents alternately and by observing the agents' treatment of the auditors (hereinafter referred to as the 2001 Osaka Audits; see below). The result of the study was that elderly home-seekers were provided with less information on housing units that were available than young home-seekers by about $30 \%$, and that the risk of the elderly's future income decreasing, the risk of their tenancy period becoming too long, and young people's preference for neighborhoods of young inhabitants might have produced housing discrimination. However, the experimental design of the study had some problems to be improved: Because the elderly auditors used were limited to single ones, and a relatively small range of data other than age were collected, so the study result did not have sufficient generality, and there were many hypotheses that could not be tested. Moreover, because the elderly auditors were asked to answer their real ages, the test results might have reflected the trend for the elderly in their early sixties too strongly.

This paper reports the outcome of a new fair housing audit (the 2002 Osaka Audits), in which improvements were added for the above-mentioned problems, and analyzes the existence of discrimination against the elderly as a whole and a variety of causes of age discrimination, using a broader range of tests of hypotheses.

This paper also uses some econometric techniques in an attempt to specify the causes of age discrimination. The U.S. has many precedent experimental studies using fair 
housing audit data mainly on racial discrimination. First, we can mention Yinger (1986) as a pioneering attempt that later became a standard for this category of studies. His paper used data of the 1981 Boston Audits, and tested linear model of the number of housing units that were available and inspected by each of the auditors.

Then Roychoudhury et al. (1992) and Page (1995) improved the empirical method in consideration of the characteristics of fair housing audit data. Ondlich et al. (1998) have a closer connection with the present paper. To deal with the characteristics of respective real estate agents that are difficult to observe, such as their ability to provide information about available housing, they used Chamberlain (1980) fixed-effects logit technique.

This paper uses the linear models adopted by Yinger (1986) to test the existence of age discrimination. Then, using the fixed-effects logit techniques used by Ondlich et al. (1998), it tests hypotheses, and verifies results using the random-effects probit technique.

The results obtained can be summarized as follows: housing discrimination against elderly home-seekers was observed on a statistically significant level. It was also suggested that the risk of the elderly's future income changing, the risk of fire caused by their negligence, the risk of their tenancy period becoming too long, and their preference for location of housing, as well as young people's preference for neighborhoods of young inhabitants, affected housing discrimination against elderly home-seekers. Finally, it was found that the patterns of restrictions on renting houses to the elderly differed according to their family structure and age.

This paper is organized as follows: Section 2 describes the data used and the estimation strategy. Section 3 discusses whether age discrimination exists in the rental housing market in Japan. Section 4 reports the hypotheses tested in relation to the causes of discrimination, Section 5, the result of estimation by the fixed-effects logit technique, and Section 6, the result of estimation by the random-effects probit technique. Section 7 is the conclusion. 


\section{Estimation Strategy}

\subsection{Data (2002 Osaka Audits)}

The data used in this paper are from a fair housing audit the author conducted in the City of Osaka and the Hokusetsu area (e.g. Ibaraki, Takatuki, Toyonaka, Suita, Settsu, Minoo) in February and March 2002 (hereinafter referred to as the 2002 Osaka Audits). Using this data, the following sections test hypotheses concerning the existence and causes of discrimination. One of the features of the analyses in this paper, as compared to existing studies, is that it controls the attributes of housing units in more detail. Controlling these attributes and the attributes given to the auditors, and analyzing the availability of units to them enable us to specify the causes of housing discrimination, which are based on unobservable differences in the attribute (e.g. risks on future income and too long tenancy period) that cannot be controlled even by the process of an audit study.

This is the same as Nakagawa (2001) and Nakagawa (2002) using the 2001 Osaka Audits. But, because the 2001 audits did not control the age of the elderly and only adopted elderly singles, the data produced by the audits lacked generality. Moreover, the data collected were limited to a relatively small scope; for example, no data were gathered about the attributes of the staff in charge at the real estate agent and about the availability of elevators in the housing unit. Therefore, the scope of hypotheses tested was limited, too. In the 2002 Osaka Audits, the technique was expanded by giving auditors the attributes of income ${ }^{1)}$, family structure (singles or couples), and age (62, 70, 77 years), considering the features of advertised housing units. In addition, a broad range of data on real estate agents and housing units was collected. The number of real estate agents studied was 197.

\subsection{Estimation Strategy for the existence of discrimination}

First, the existence of discrimination is described by the incidence of discrimination and is tested using a linear model about the number of units that are available.

The simple net measure of the incidence of discrimination, which is obtained by 
deducting the ratio of real estate agents giving unfavorable treatment to majorities from the ratio of agents giving unfavorable treatment to minorities, is adopted.

The existence of discrimination regarding the number of units that are available is tested by the following linear model using the generalized least squares (GLS) procedure:

$$
Q_{i}^{a}=\alpha_{1}+\beta_{1} W_{i}^{a}+\lambda_{i}
$$

where, $i$ is the index of the real estate agent and $a$ is that of auditor visits. There are two types of visit: visit by an elderly home-seeker $(a=2)$ and visit by a young home-seeker $(a=1)$. Also,

$Q_{i}^{a} \quad$ : number of units that are available offered to visit $a$ by real estate agent $i$;

$W_{i}^{a} \quad$ : dummy variable that is 1 if visit $a$ to real estate agent $i$ is by an elderly auditor, and is 0 if such visit is by a young auditor;

$\lambda_{i}$ : error component shared by the team mates, such as the characteristics of the real estate agent and the market environment.

Because the constant term is the average number of units offered to young home-seekers and $\beta_{1}$ is the difference in the mean treatment of young home-seekers and elderly home-seekers, the sign of $\beta_{1}$ is expected to be negative if discrimination exists.

\subsection{Estimation Strategy for the causes of discrimination}

In the test of hypotheses for the causes of discrimination, both the fixed-effects logit technique and the random-effects probit technique are used to deal with the hetrogeneity of real estate agents.

\section{(1) Fixed-effects logit technique}

The fixed-effects logit technique used by Ondlich et al. (1998) is employed here, adding information about respective housing units to it. First, the existence of 
particular behavior of real estate agents is specified as follows:

$$
\begin{aligned}
& \operatorname{Pr}\left(A_{i j}^{a}=1 \mid W, X, Y\right) \\
& =F\left(\delta_{2} W_{i}^{a}+\beta_{2} X_{i}^{a}+\gamma_{2} Y_{i j}^{a}+\beta_{2}^{\prime} W_{i}^{a} X_{i}^{\prime 2}+\gamma_{2}^{\prime} W_{i}^{a} Y_{i j}^{\prime 2}+\alpha_{2 i}\right)
\end{aligned}
$$

where, $j$ is the index of units to be audited, and it is assumed that these units belong to Group $i$; here $i$ represents the real estate agent and $j$, the units the agent has in stock. As in Equation (1), $a$ is the index of auditor visits. $A_{i j}^{a}$ is a dummy variable that is 1 if the agent offers the unit to the visitor and is 0 in all other cases ${ }^{2)} . W_{i}^{a}$ is a dummy variable that is 1 if visit $a$ to real estate agent $i$ is by an elderly auditor and 0 if the visit is by a young auditor. $X_{i}^{a}$ is the vector of other explanatory variables concerning auditor visit $a$ to real estate agent $i$. For example, the variables are location of the office of real estate agent $i$ and the sex and age of the staff in charge who receives the auditor. $Y_{i j}^{a}$ is the vector of explanatory variables concerning units $j$ real estate agent $i$ has in stock, which include such attributes of housing units as rent, age, and structure. $\mathrm{X}^{\prime}$ and $\mathrm{Y}^{\prime}$ are the variables in connection with discrimination.

To deal with unobservable characteristics of each auditor and real estate agent, hypotheses on age discrimination can be tested by evaluating Equation (3) below by the fixed-effects logit technique following Chamberlain (1980):

$$
\begin{aligned}
& \operatorname{Pr}\left(A_{i j}^{2}-A_{i j}^{1}=1 \mid A_{i j}^{1}+A_{i j}^{2}=1 ;\left(X^{2}-X^{1}\right),\left(Y^{2}-Y^{1}\right), X^{2}, Y^{2}\right) \\
& =F\left(\delta_{2}+\beta_{2}^{\prime} X_{i}^{\prime 2}+\gamma_{2}^{\prime} Y_{i j}^{\prime 2}+\beta_{2}\left(X_{i}^{2}-X_{i}^{1}\right)+\gamma_{2}\left(Y_{i j}^{2}-Y_{i j}^{1}\right)\right)
\end{aligned}
$$

To measure the average level of discrimination by the constant term, this paper tests hypotheses using Equation (4) formulated by reformulating Equation (3):

$$
\begin{aligned}
& \operatorname{Pr}\left(A_{i j}^{2}-A_{i j}^{1}=1 \mid A_{i j}^{1}+A_{i j}^{2}=1 ;\left(X^{2}-X^{1}\right),\left(Y^{2}-Y^{1}\right),\left(X^{2}-\bar{X}\right),\left(Y^{2}-\bar{Y}\right)\right) \\
& =F\left(\delta_{2}^{o}+\beta_{2}^{\prime}\left(X_{i}^{\prime 2}-\bar{X}^{\prime}\right)+\gamma_{2}^{\prime}\left(Y_{i j}^{\prime 2}-\bar{Y}^{\prime}\right)+\beta_{2}\left(X_{i}^{2}-X_{i}^{1}\right)+\gamma_{2}\left(Y_{i j}^{2}-Y_{i j}^{1}\right)\right)
\end{aligned}
$$

where, $\bar{X}$ and $\bar{Y}$ are the averages of $\mathrm{X}$ and $\mathrm{Y}$, and $\delta_{2}{ }^{o}=\delta_{2}+\beta_{2}^{\prime} \bar{X}^{\prime}+\gamma_{2}^{\prime} \bar{Y}^{\prime}$. $\left(X_{i}^{2}-X_{i}^{1}\right)$ has a value other than 0 only if different individuals serve the auditors, 
while $\left(Y_{i j}^{2}-Y_{i j}^{1}\right)$ is always 0 , because it is assumed that the sum of the units offered to elderly home-seekers and those offered to young home-seekers is equal to the number of units the real estate agent has in stock.

\section{(2) Random-effects probit technique}

But, because the estimation by the fixed-effects logit technique can use the restricted data meeting the condition that $A_{i}^{1}+A_{i}^{2}=1$, much information may become unusable because it belies this supposition. Thus, this paper uses the random-effects probit technique, a binary choice model that is capable of dealing with heterogeneity between individuals. More specifically, the following equation formulated by modifying Equation (2) is employed:

$$
\begin{aligned}
& \operatorname{Pr}\left(A_{i j}^{a}=1 \mid W, X, Y,\left(X^{2}-\bar{X}\right),\left(Y^{2}-\bar{Y}\right)\right) \\
& =F\left(\delta_{3}^{o} W_{i}^{a}+\beta_{3} X_{i}^{a}+\gamma_{3} Y_{i j}^{a}+\beta_{3}^{\prime} W_{i}^{a}\left(X_{i}^{\prime 2}-\bar{X}^{\prime}\right)+\gamma_{3}^{\prime} W_{i}^{a}\left(Y_{i j}^{\prime 2}-\bar{Y}^{\prime}\right)+\alpha_{3 i}\right)
\end{aligned}
$$

Equation (5) can measure the level of discrimination that average elderly home-seekers will experience using the coefficient of the dummy variable for the elderly.

\section{Existence of age discrimination}

Using the data from the 2002 Osaka Audits, this section describes the existence and level of age discrimination in the rental housing market. First, Table 1 shows the simple net measure of incidence of discrimination. Although the most blatant forms of housing discrimination, such as providing no information on the advertised units or similar units to the elderly, are relatively rare, the possibility that elderly home-seekers encounter real estate agents who would give them only a small amount of information is higher than that for young home-seekers by about $40 \%$. The probability that the elderly meet agents who would ask if they have a guarantor for renting a housing unit only to elderly home-seekers is higher by a similar ratio, too. These trends are roughly the same as those observed in the 2001 Osaka Audits, indicating that although the Act for Stable Living of the Elderly (hereinafter referred to as the "SLE") was enforced in 2001, no great changes have occurred yet as to the existence and level of age 
discrimination. $^{3)}$

(Table 1. inserts here)

Next, the result of estimation of the number of units that are available by the GLS procedure is shown by Equation (6): ${ }^{4)}$

$(\text { Number of units available) })_{a i}=4.6954-1.5533$ (dummy variable for the elderly) ${ }_{i}$

$$
(0.2084 * * *)(0.2371 * * *)
$$

$\mathrm{R}^{2}=0.711$, number of samples: 394

Note: Figures with $* * *$ are significant on the $1 \%$ level.

The figures in parentheses are standard errors, and both are significantly different from 0 at the $1 \%$ level. The sign of the dummy variable for the elderly is negative, which is consistent with the hypothesis that there exists age discrimination. According to the level of discrimination detected, young home-seekers were offered 4.70 housing units on average, but elderly home-seekers were offered only 3.14 units, fewer than those for young home-seekers by 1.55 units, which means there exists a difference of about $33 \%$ between the two age groups. In the analysis of Nakagawa (2001) that used data from the 2001 Osaka Audits, a difference of $27 \%$ was observed, suggesting that there was no substantial change between 2001 and 2002 as to discrimination in the number of units that were available.

\section{The hypotheses tested}

The hypotheses about the causes of age discrimination are tested in the following sections. First, this section explains the hypotheses used in the tests.

In Japan, there have been few reports on discrimination based on prejudice, such as agism. Also, the reasons that elderly home-seekers were unable to rent housing units, which were mentioned in a questionnaire sent to 117 property management companies 
by the Japan Property Management Association ("Report of the Investigation on the Situation of Elderly Tenancy," April 2000; hereinafter referred to as the "ISET"; see Table 2) show that it is highly likely that age discrimination in rental housing market in Japan is statistical discrimination, i.e. discrimination based not on prejudice but on the physical and economical characteristics of elderly home-seekers. Nakagawa (2001) and Nakagawa (2002) concluded that the hypothesis that the risk of the elderly's future income decreasing, the risk of their tenancy period becoming too long, and young people's preference for neighborhoods with young inhabitants affect restrictions on renting houses to the elderly was supported by the data collected. These hypotheses were proposed on the basis of the results obtained from the ISET. But, because the 2001 Osaka Audits was based on only one type of the elderly, i.e. elderly singles, they were unable to entirely test the motives listed in Table 2 and to fully control various factors affecting restrictions on renting houses. Thus, this paper formulates six hypotheses for economically explaining age discrimination as to almost all of the motives in Table 2, that is, "community preference hypothesis," "disaster prevention hypothesis," "elderly preference hypothesis," "future income hypothesis," "tenancy period hypothesis," and "real estate agent hypothesis," and tests these hypotheses using the data from the 2002 Osaka Audits. The explanatory variables used and their descriptions are shown in Table 3. Each of the hypotheses is explained below.

(Table 2. and Table 3. inserts here)

\section{(1) Community preference hypothesis}

The respondents of the ISET mentioned these two reasons for being negative about renting housing units to the elderly: "difficulty in taking action when an elderly tenant weakens or becomes ill" and "liability of the elderly to get into trouble with other tenants." They are staff of property management companies, but their answers can be seen as reflecting the views of existing tenants and potential young tenants. The 
community preference hypothesis assumes that restrictions on renting houses to the elderly arise because elderly people residing in the neighborhood brings disutility to existing or potential young inhabitants due to the elderly's physical and life-style characteristics.

The probability that results in such situations as the tenant's physical conditions worsened with no proper home-nursing provided and the tenant died is higher among single-member households and is expected to increase with aging. Therefore, the coefficients of "singles," the variable representing single-member households, "the middle-stage elderly," the variable representing the elderly of 70 years, and "the late-stage elderly," the variable representing the elderly of 77 years, are expected to have a negative sign.

It is also expected that landlords in the neighborhood having more young inhabitants will receive complaints and will lose tenants if they rent units to elderly home-seekers ${ }^{5}$. Therefore, a positive sign is expected for the "ratio of elderly inhabitants in the neighborhood of units," the variable expressing the percentage of elderly inhabitants in the area where the housing unit is located. At the same time, it is anticipated that restrictions on renting houses to the middle- and late-stage elderly, who have relatively high risks of changes in physical conditions, will reflect more elastically to this ratio.

\section{(2) Disaster prevention hypothesis}

This hypothesis is associated with the reason "safety and management problems of housing, including fires caused by negligence," mentioned ISET. If a fire broke out in their housing unit, the landlord and inhabitants of the neighborhood would lose their assets.

This risk is higher if tenants are singles and are middle- or late-stage elderly people, and restrictions on renting houses will become greater accordingly. Moreover, considering initial fire-fighting activities by inhabitants in the neighborhood, an area with a higher ratio of elderly inhabitants will have a higher risk of the fire spreading to it. If such an area accepts new elderly tenants, who have a higher possibility of causing a fire by their negligence, it will result in the risk of heavier damage than in the areas 
with lower ratios of the elderly. Thus, there is a possibility that existing tenants or landlords in such an area have a motive to avoid raising the ratio of elderly in their neighborhood further.

Therefore, this hypothesis predicts that the "ratio of elderly inhabitants in the neighborhood of units" will have a negative sign, and anticipates also that restrictions on renting houses to middle- and late-stage elderly home-seekers, who are more likely to cause fires by their negligence, will reflect more elastically to this ratio. As noted, the community preference hypothesis and the disaster prevention hypothesis predict opposite signs as to the "ratio of elderly inhabitants in the neighborhood of units."

\section{(3) Elderly preference hypothesis}

This hypothesis is related to the reason "limited availability of units with structure and equipment fit for the elderly" cited in the ISET. It assumes that in anticipation of elderly home-seekers' preferences, the landlord refrains from offering them housing units that do not meet the expected preferences. In this paper, the units for which the elderly have a preference are assumed to be those with large floor areas, on lower floors, equipped with elevators ${ }^{6}$, and close to a station.

\section{(4) Future income hypothesis}

This hypothesis is associated with the reason "fear of rent arrears" mentioned in the ISET. Behind this fear are such facts as that elderly workers are more liable to be fired in a restructuring plan, that they have difficulty finding a new job once fired, and that they are apt to suffer from changes in physical conditions, which may make it difficult for them to pay rent regularly ${ }^{7)}$. This hypothesis expects more blatant discrimination against singles and middle- and late-stage elderly people, and rental units with higher rents. It is also expected that restrictions on renting houses to middle- and late-stage elderly people, for whom these risks are higher, will reflect more elastically to rents.

\section{(5) Tenancy period hypothesis}

This hypothesis is related to the reason "tendency of too long a tenancy period" 
mentioned in the ISET. This motive is connected to the difficulty of raising rents for incumbent tenants under the Japanese Tenant Protection Law ${ }^{8)}$.

If the landlord admits a tenant who stays for a long time, he or she has the risk of having to give up the possibility of increasing the rent in the future. Because the landlord must abandon the chance to raise the rent for the maximum period of the remaining life of the rental housing unit, he or she will put greater restrictions on renting units with a longer remaining life at the time of renting. In other words, these restrictions will be severer for housing with a structure having a longer remaining life, such as newly built units and steel and reinforced concrete composite construction (RC) units.

Therefore, positive coefficients are anticipated for the "age of housing unit" and "non-RC units." On the other hand, the longer remaining life expectancy elderly tenants have, the longer tenancy period they are expected to have. Thus, it is expected that restrictions on renting housing because of these motives will be greater for early-stage elderly home-seekers, so these restrictions on middle-stage and late-stage elderly home-seekers will not reflect elastically to the "age of housing unit."

\section{(6) Real estate agent hypothesis}

This hypothesis holds that the more service years and the greater need for long-term relations with the landlord the staff of the real estate agent have, the more careful they would be in renting houses to minorities. This paper adopts the age and sex ${ }^{9)}$ of the staff as explanatory variables.

The hypothesis that real estate agents having offices in a neighborhood with elderly residents are more lenient to elderly home-seekers is also classified into this category.

Table 4 shows the signs that each of the explanatory variables is likely to have for each of the six hypotheses. If discrimination exists, all of the hypotheses are expected to have a negative sign as to constant terms in the fixed-effects logit model and as to the dummy variable "the elderly" used in the random-effects probit model. 
(Table 4. inserts here)

\section{Estimation result obtained by the fixed-effects logit technique \\ 5.1 Estimation result of real estate agent data}

(Table 5. inserts here)

First, the estimation result of Equation (4) using real estate agent data, i.e., the "number of units that are available" ( $A_{i}^{a}=1$ if the number of units that are available to one auditor of a pair is larger than that for the other auditor at the real estate agent, and $A_{i}^{a}=0$ in all other cases) and "questions about guarantors" ( $A_{i}^{a}=1$ if a question about a guarantor is asked at the real estate agent, and $A_{i}^{a}=0$ in all other cases), is reported in Table 5. The coefficients reported are those of the elderly auditor's explanatory variables in Equation (4) $\left(\beta_{2}^{\prime}\right)$ and those of the differentials between the auditors $\left(\beta_{2}\right)$. 10)

As for the "number of units that are available," a constant term that is significant and has a negative sign is obtained, the case is very likely that the number of units offered to elderly home-seekers is less than that offered to young home-seekers. Significant coefficients with a negative sign are also gained for the "late-stage elderly," "singles," and the "ratio of elderly inhabitants in the neighborhood of units," which are all consistent with the "disaster prevention hypothesis." Also, the negative coefficient of "male real estate agents" is consistent with the "real estate agent hypothesis."

In "questions about guarantors," the constant term has a positive and significant coefficient. But note that an auditor was considered to be disfavored, if he, but not his teammate, was asked about his guarantors. So this variable should be evaluated by the 
opposite sign to the sign actually obtained. The positive and significant coefficients for the "middle-stage elderly" and the "late-stage elderly" suggest that home-seekers with a high risk of a change in physical conditions are asked to state that they have a guarantor, whereas the positive and significant coefficient for "rents" indicates that the higher the rent is, the more likely it is that the home-seekers are requested to affirm that they have a guarantor. These results are both consistent with the "future income hypothesis." The positive coefficient for "differentials of male real estate agents" is consistent with the "real estate agent hypothesis." ${ }^{11)}$

\subsection{Estimation result of data for housing units offered}

(Table 6. inserts here)

Table 6 summarizes the estimation result, using Equation (4), of the availability to home-seekers of rental housing units that real estate agents have in stock. It is assumed that the total units offered to elderly and young home-seekers are all the units meeting the home-seekers' requests for housing attributes that agents have in stock.

The constant term is estimated significant with a negative sign for rental units for singles, suggesting that elderly home-seekers on average tend to be provided with less information about units that are available. In the case of units for couples, the constant term also has a negative sign, but is not significant. The test result is outlined for each of the hypotheses below.

First, the "community preference hypothesis" and the "disaster prevention hypothesis" are examined. As stated above, these hypotheses anticipate opposite signs for the "ratio of elderly inhabitants in the neighborhood of units" and the cross term of this ratio and the dummy variables for middle-stage and late-stage elderly people. Regarding units for singles, negative and significant coefficients are elicited for the "late-stage elderly" and the cross term of the "middle-stage elderly" and the "ratio of elderly 
inhabitants in the neighborhood of units." As the "disaster prevention hypothesis" suggests, this result shows that the landlord's intention to avoid the ratio of elderly inhabitants from increasing. But the "ratio of elderly inhabitants in the neighborhood of units," the coefficient based on the early-stage elderly, has a positive sign, so the "disaster prevention hypothesis" was supported by the results of, or results consistent with this hypothesis are obtained for middle-stage and the late-stage elderly only.

Regarding units for couples, no results that support the "disaster prevention hypothesis" are obtained. Because that elderly singles are often unable to be as careful with fire as elderly couples, this result can be interpreted as being consistent, considering that the landlord will have a strong motive to avoid concentration of elderly singles, who are more risky than elderly couples. Rather, the positive sign of the "ratio of elderly inhabitants in the neighborhood of units" and the cross term of the "middle-stage elderly" and the "ratio of elderly inhabitants in the neighborhood of units" indicates, as does the result gained for early-stage elderly singles referred to above, the possibility that both elderly couple and early-stage elderly singles face discrimination in the same direction as the "community preference hypothesis." This will be confirmed later in the report on the test results using the random-effects probit technique.

In addition, a negative and significant coefficient is estimated for units for singles as to "distance to the nearest station." This shows the tendency for convenient housing units near a station being offered more often to elderly home-seekers, which is consistent with the "elderly preference hypothesis." The positive and significant coefficients for "non-RC units" and the "age of housing unit" and the negative and significant coefficient for the cross term of "late-stage elderly" and the "age of housing unit" are consistent with the "tenancy period hypothesis."

Finally, a negative and significant coefficient is obtained for units for couples as to "male real estate agents," which supports the "real estate agent hypothesis."

The test results using the fixed-effects logit technique can be summarized as follows: 
i The "number of units that are available" and "questions about guarantors," where the test was conducted using real estate agent data, both supported the "real estate agent hypothesis." The former estimation also supported the "disaster prevention hypothesis," and the latter also supported the "future income hypothesis."

ii The test using data of units for singles that real estate agents has in stock supported the "elderly preference hypothesis" and the "tenancy period hypothesis." As for the middle- and late-stage elderly, the "disaster prevention hypothesis" was supported, or the result consistent with this hypothesis was gained.

iii The test of units for couples supported the "real estate agent hypothesis."

\section{Estimation result using the random-effects probit technique}

The estimation using the fixed-effects logit technique reported in the preceding section used the data on condition that the sum of two observations is expressed by $A_{i}^{1}+A_{i}^{2}=1$, and the information on many housing units that did not satisfy this condition could not be used. Of the data on 1,384 units that are available, only that of 178 units for singles and of 116 units for couples were usable. This section reports the estimation result using the random-effects probit technique, which can handle more samples than the fixed-effects logit technique.

\subsection{Estimation result of real estate agent data}

(Table 7. inserts here)

The estimation result for the "number of units that are available" and "questions about guarantors" is shown in Table 7. As for the former estimation, the coefficient of the "elderly" is estimated to be negative and significant, suggesting that discrimination exists. Also, as in the estimation result of Equation (4), significant negative 
coefficients are estimated for "late-stage elderly," "singles," "male real estate agents," and "ratio of elderly inhabitants in the neighborhood of units." A significant positive coefficient is obtained for "non-RC units," too. The signs of these coefficients are all consistent with the "disaster prevention hypothesis," "tenancy period hypothesis," and "real estate agent hypothesis."

As for "questions about guarantors," a significant positive coefficient is obtained for the "elderly," which indicates that there exists discrimination. A positive and significant coefficient is estimated for "singles," too. No significant results are obtained for the "middle-stage elderly," the "late-stage elderly," and "rents," but the coefficients of the first two variables have the same signs as the estimation result of Equation (4).

\subsection{Estimation result of data of housing units offered}

(Table 8. inserts here)

The test result of rental units for singles and couples is shown in Table 8. Regarding units for singles, the coefficient of the "elderly" has a negative sign, but is not significant. As in the estimation result for Equation (4), the "late-stage elderly", "non-RC units," "distance to the nearest station," the "age of housing unit," and the cross term of the "middle-stage elderly" and the "ratio of elderly inhabitants in the neighborhood of units" are significant. Because the "middle-stage elderly" and the cross term of the "late-stage elderly" and the "ratio of elderly inhabitants in the neighborhood of units" are also estimated to be significant and negative, the "elderly preference hypothesis" and "tenancy period hypothesis," as well as the "disaster prevention hypothesis" for the middle- and late-stage elderly, are supported robustly. No significant coefficient is obtained for the cross term of the "late-stage elderly" and 
the "age of housing unit," but the sign is the same as that obtained for Equation (4).

In the case of units for couples, the coefficient of the "elderly" is negative and significant, indicating that discrimination exists. Also, as with the fixed-effects logit technique, a significant negative coefficient is obtained for "male real estate agents," which is consistent with the "real estate agent hypothesis." The "tenancy period hypothesis" is not supported in the estimation using the fixed-effects logit technique, but the estimation using the random-effects probit technique produces a significant result that is consistent with this hypothesis as to "non-RC units" and the cross term of the "late-stage elderly" and the "age of housing unit". A negative coefficient is also obtained for the cross term of the "late-stage elderly" and "rents," which is consistent with the "future income hypothesis." In addition, a positive and significant coefficient of the cross term of the "late-stage elderly" and the "ratio of elderly inhabitants in the neighborhood of units" is obtained for elderly couples. Together with the positive sign of the "ratio of elderly inhabitants in the neighborhood of units", is consistent with, or supports, the "community preference hypothesis."

As noted, the following facts could be confirmed using the random-effects probit technique:

i The "number of units that are available," real estate agent data, supported the "disaster prevention hypothesis," "tenancy period hypothesis," and "real estate agent hypothesis."

ii The data on housing units for singles supported, as with the fixed-effects logit model, the "elderly preference hypothesis" and "tenancy period hypothesis." Similarly, the "disaster prevention hypothesis" was supported for the middle- and late-stage elderly.

iii The data on units for couples supported the "real estate agent hypothesis" as with the fixed-effects logit model, and the "tenancy period hypothesis," "community preference hypothesis," and "future income hypothesis" were also supported. 
From the above result and the result attained in the test using the fixed-effects logit model, it can be summarized, especially as to the relation between neighborhood and age discrimination, that while the "disaster prevention hypothesis" was supported for the middle- and late-stage elderly singles, a result consistent with, or supporting, the "community preference hypothesis" was obtained for the early-stage elderly singles and elderly couples.

\section{Conclusion}

This paper tested the six hypotheses on the causes of age discrimination in the rental housing market, using the data from the 2002 Osaka Audits and by controlling the attributes of housing units in detail. The fixed-effects logit technique and randomeffects probit technique were adopted for this test. Table 9 summarizes the sign conditions predicted by each of the hypotheses and the signs of estimated significant coefficients. The test result of the hypotheses can be summarized as follows:

i The result produced was that discrimination was practiced based on the characteristics of the elderly, i.e. liability to change in future income, and tendency toward too long a tenancy period("future income hypothesis" and "tenancy period hypothesis").

ii As for the "elderly preference hypothesis," which holds that real estate agents take into consideration elderly home-seekers' preferences when offering them information about units that are available, a significant result was attained regarding distance from the nearest station.

iii It was concluded that male real estate agents are more likely to practice age discrimination, because they have a greater need to keep a good, long-term relationship with the landlord("real estate agent hypothesis").

iv It was found that, as for relations between the neighborhood and age discrimination, the pattern of discrimination differs according to family structure and age. That is, a result consistent with, or supporting, the "disaster prevention hypothesis" was 
produced for the middle- and late-stage elderly singles, whereas a result consistent with, or supporting, the "community preference hypothesis" was obtained for the early-stage elderly singles and elderly couples.

(Table 9. inserts here)

The results of the two audits, which are reported by this paper and by Nakagawa (2001) and Nakagawa (2002), explicitly show that age discrimination exists in the rental housing market and that a considerable part of housing discrimination against the elderly is statistical discrimination in tenant selection. This test result that housing discrimination against the elderly can be explained by hypotheses about landlords' reasonable tenant selection suggests that policy interventions should aim not at the prohibitive control of the age discrimination, but instead at selecting appropriate policy objectives and means based on evaluations of externalities or distribution problems. One of the problems to be dealt with is problems of distribution associated with higher search costs for the elderly people. Yinger (1997) offers useful information on assessing these additional costs, which is a precondition for policy interventions.

The policies now introduced in Japan in relation to restrictions on renting houses to the elderly include (1) development of public housing units and other units for giving the elderly renting preference, (2) diffusion of information about housing that are available to the elderly, and (3) decrease in the risk of the elderly being in arrears with rent by the rent guarantee system. Encouraging the fixed term house lease system ${ }^{12)}$ is also an important policy theme. These policies will basically have the effect of solving problems of distribution associated with restrictions on renting houses to the elderly. But the test result of this paper, reasonable reasons such as risk related to the elderly's future income and their tenancy period, considerably affect age discrimination, indicated that the use of the fixed term house lease system and the policies described in (2) and (3) above will be especially effective. In addition, as shown in Table 10, the 
pattern of age discrimination differs according to the elderly's family structure and age, which means the need for carefully designing the system. Late-stage elderly singles face stronger restrictions on renting houses and thus have a greater need for distribution policies.

(Table 10. inserts here)

When designing housing policies for the elderly, careful consideration is also required for the relation between age discrimination and the neighborhood. If traditional distribution policies are simply introduced, the concentration of the elderly in a neighborhood of elderly inhabitants might result. Multidisciplinary approaches, in cooperation with the engineering approach, will be necessary for evaluating the externalities brought about by a concentration of elderly inhabitants. And the policies to be studied include distribution policies that would promote deconcentration, such as housing vouchers supplied only to those who move to a community with a low minority ratio, which were adopted for the Moving to Opportunity Demonstration, a policy experimented in the U.S. But discrimination against the middle- and late-stage elderly based on the risk of fires caused by negligence may not be much reduced even by these policies. In such a case, the use of public housing units, in close cooperation with the welfare policy, will be effective. 
Table 1. Incidence of discrimination measured by the 2001 Osaka Audits and 2002 Osaka Audits

\begin{tabular}{|l|c|c|}
\hline & $\begin{array}{c}\text { Simple net measure of incidence } \\
\text { of discrimination (2002) }\end{array}$ & $\begin{array}{c}\text { Simple net measure of incidence } \\
\text { of discrimination (2001) }\end{array}$ \\
\hline Availability of advertised units ${ }^{1)}$ & $6.38 \%$ & $8.77 \%$ \\
\hline Availability of similar units $^{2)}$ & $7.61 \%$ & $6.09 \%$ \\
\hline No. of units available $^{3)}$ & $44.67 \%$ & $37.39 \%$ \\
\hline Questions about guarantors $^{4)}$ & $43.15 \%$ & $43.95 \%$ \\
\hline Questions about age $^{5)}$ & $-0.51 \%$ & $0.92 \%$ \\
\hline Questions about occupation $^{6)}$ & $-6.60 \%$ & \\
\hline Questions about income $^{7)}$ & $7.14 \%$ & \\
\hline Requests for second contacts $^{8)}$ & $3.55 \%$ & $5.31 \%$ \\
\hline
\end{tabular}

Notes:

1) Figures are those obtained by deducting the ratio of real estate agents who offered advertised units to elderly auditors only from that of agents who offered such units to young auditors only.

2) The same as 1$)$.

3) Figures are those obtained by deducting the ratio of real estate agents who offered more units to elderly auditors from that of agents who offered more units to young auditors.

4) Figures are those obtained by deducting the ratio of real estate agents who asked questions about guarantors to young auditors only from that of agents who asked such questions to elderly auditors only.

5) to 7) The same as 4).

8) Figures are those obtained by deducting the ratio of real estate agents who requested a second contact to elderly auditors only from that of agents who made such request to young auditors only. 
Table 2. Reasons that elderly home-seekers were unable to rent housing units

\begin{tabular}{|l|c|}
\hline \multicolumn{1}{|c|}{ Reason } & $\begin{array}{c}\text { No. of real estate } \\
\text { agents concerned }\end{array}$ \\
\hline Difficulty in taking action when an elderly tenant weakens or becomes ill & 93 \\
\hline The landlord's wish to avoid elderly tenants & 81 \\
\hline Safety and management problems, including the risk of fires caused by negligence & 68 \\
\hline No guarantors & 56 \\
\hline Limited availability of units with structure and equipment fit for the elderly & 44 \\
\hline Fear of rent arrears & 28 \\
\hline Rents unacceptable to elderly home-seekers & 16 \\
\hline Tendency of too long a tenancy period & 10 \\
\hline Liability of the elderly to get into trouble with other tenants & 4 \\
\hline Carelessness with rules & 1 \\
\hline
\end{tabular}

Source: "Report of the Investigation on the Situation of Elderly Tenancy," the Japan Property Management Association, 2001 
Table 3. Explanatory variables used

\begin{tabular}{|c|c|}
\hline Variable & Description \\
\hline The elderly & $\begin{array}{l}\text { Dummy variable is } 1 \text { if the auditor is an elderly one and } 0 \text { if the auditor is a } \\
\text { young one. 1) }\end{array}$ \\
\hline Singles & $\begin{array}{l}\text { Dummy variable is } 1 \text { if the auditor is a single and } 0 \text { if the auditor is one } \\
\text { member of a couple. }\end{array}$ \\
\hline The middle-stage elderly & $\begin{array}{l}\text { Dummy variable is } 1 \text { if the elderly auditor is } 70 \text { years and } 0 \text { in all other } \\
\text { cases. }\end{array}$ \\
\hline The late-stage elderly & $\begin{array}{l}\text { Dummy variable is } 1 \text { if the elderly auditor is } 77 \text { years and } 0 \text { in all other } \\
\text { cases. }\end{array}$ \\
\hline Male real estate agents & $\begin{array}{l}\text { Dummy variable is } 1 \text { if the staff at the real estate agent who dealt with the } \\
\text { auditor was a male and } 0 \text { in all other cases. }\end{array}$ \\
\hline Young real estate agents & $\begin{array}{l}\text { Dummy variable is } 1 \text { if the staff at the real estate agent who dealt with the } \\
\text { auditor was considered to be } 40 \text { years or less and } 0 \text { in all other cases. }\end{array}$ \\
\hline Rents & Rents of housing units (including common service fees) \\
\hline No. of tatami & No. of tatami of housing units \\
\hline Non-RC units & $\begin{array}{l}\text { Dummy variable is } 1 \text { if the unit is wooden or of steel-frame construction } \\
\text { and } 0 \text { if it is of steel and reinforced concrete composite construction (RC). }\end{array}$ \\
\hline $\begin{array}{l}\text { Distance to the nearest } \\
\text { station }\end{array}$ & Distance on foot from the unit to the nearest station \\
\hline Floor number of unit & Floor number where the unit exists \\
\hline Elevators & Dummy variable is 1 if the unit has elevators and 0 if it has no elevators 2 ) \\
\hline $\begin{array}{l}\text { Ratio of elderly inhabitants } \\
\text { in the neighborhood of real } \\
\text { estate agents }\end{array}$ & $\begin{array}{l}\text { Ratio of elderly inhabitants in the ward or municipality where the real } \\
\text { estate agent has its office }\end{array}$ \\
\hline $\begin{array}{l}\text { Ratio of elderly inhabitants } \\
\text { in the neighborhood of } \\
\text { units }\end{array}$ & $\begin{array}{l}\text { Ratio of elderly inhabitants in the cho or chome (small administrative } \\
\text { divisions of a city) where the unit is located }\end{array}$ \\
\hline $\begin{array}{l}\text { Differentials of male real } \\
\text { estate agents }\end{array}$ & $\begin{array}{l}\text { Differentials of "Male real estate agents" between elderly and young } \\
\text { home-seekers }\end{array}$ \\
\hline $\begin{array}{l}\text { Differentials of young real } \\
\text { estate agents }\end{array}$ & $\begin{array}{l}\text { Differentials of "Young real estate agents" between elderly and young } \\
\text { home-seekers }\end{array}$ \\
\hline Wards and municipalities & $\begin{array}{l}\text { Dummy variable concerning the ward or municipality where the unit is } \\
\text { located }\end{array}$ \\
\hline
\end{tabular}

Notes:

1) The variable "elderly" is used in Tables 7 and 8.

2) It is assumed that housing units with five floors or more had elevators even if it was not known during the audits whether they had elevators. 
Table 4. Signs of coefficients expected by the six hypotheses

\begin{tabular}{|c|c|c|c|c|c|c|}
\hline & $\begin{array}{l}\text { Community } \\
\text { preference }\end{array}$ & $\begin{array}{l}\text { Disaster } \\
\text { prevention }\end{array}$ & $\begin{array}{l}\text { Elderly } \\
\text { preference }\end{array}$ & $\begin{array}{l}\text { Future } \\
\text { income }\end{array}$ & $\begin{array}{c}\text { Tenancy } \\
\text { period }\end{array}$ & $\begin{array}{l}\text { Real } \\
\text { estate } \\
\text { agent }\end{array}$ \\
\hline Singles & $<0$ & $<0$ & & $<0$ & & \\
\hline The middle-stage elderly & $<0$ & $<0$ & & $<0$ & $>0$ & \\
\hline The late-stage elderly & $<0$ & $<0$ & & $<0$ & $>0$ & \\
\hline Male real estate agents & & & & & & $<0$ \\
\hline Young real estate agents & & & & & & $>0$ \\
\hline Rents & & & & $<0$ & & \\
\hline No. of tatami & & & $>0$ & & & \\
\hline Non-RC units & & & & & $>0$ & \\
\hline Distance to the nearest station & & & $<0$ & & & \\
\hline Age of housing unit & & & & & $>0$ & \\
\hline Floor number of unit & & & $<0$ & & & \\
\hline Elevators & & & $>0$ & & & \\
\hline $\begin{array}{l}\text { Ratio of elderly inhabitants in the } \\
\text { neighborhood of real estate agents }\end{array}$ & & & & & & $>0$ \\
\hline $\begin{array}{l}\text { Ratio of elderly inhabitants in the } \\
\text { neighborhood of units }\end{array}$ & $>0$ & $<0$ & & & & \\
\hline The middle-stage elderly * rents & & & & $<0$ & & \\
\hline The late-stage elderly * rents & & & & $<0$ & & \\
\hline $\begin{array}{l}\text { The middle-stage elderly * age of housing } \\
\text { unit }\end{array}$ & & & & & $<0$ & \\
\hline $\begin{array}{l}\text { The late-stage elderly * age of housing } \\
\text { unit }\end{array}$ & & & & & $<0$ & \\
\hline $\begin{array}{l}\text { The middle-stage elderly * ratio of elderly } \\
\text { inhabitants in the neighborhood of units }\end{array}$ & $>0$ & $<0$ & & & & \\
\hline $\begin{array}{l}\text { The late-stage elderly * ratio of elderly } \\
\text { inhabitants in the neighborhood of units }\end{array}$ & $>0$ & $<0$ & & & & \\
\hline The elderly or constant term & $<0$ & $<0$ & $<0$ & $<0$ & $<0$ & $<0$ \\
\hline Differentials of male real estate agents & & & & & & $<0$ \\
\hline Differentials of young real estate agents & & & & & & $>0$ \\
\hline
\end{tabular}


Table 5. Estimation result of real estate agent data by the fixed-effects logit technique

The middle-stage elderly

The late-stage elderly

Singles

Male real estate agents

Young real estate agents

Rents

No. of tatami

Non-RC units

Distance to the nearest station

Age of housing unit

Floor number

Elevators

Ratio of elderly inhabitants in the neighborhood of real estate agents

Ratio of elderly inhabitants in the neighborhood of units

Differentials of male real state agents

Differentials of young real estate agents

Constant term

No. of data

$x^{2}$

\begin{tabular}{|c|c|c|c|}
\hline \multicolumn{2}{|c|}{ No. of units available } & \multicolumn{2}{|c|}{ Questions about guarantors } \\
\hline Coefficient & $\begin{array}{l}\text { Standard } \\
\text { error }\end{array}$ & Coefficient & $\begin{array}{c}\text { Standard } \\
\text { error }\end{array}$ \\
\hline 0.0636 & 0.43935 & $4.5530 * *$ & 2.2504 \\
\hline$-1.1103^{*}$ & 0.6370 & $5.2790^{*}$ & 2.9188 \\
\hline$-1.3994^{*}$ & 0.7699 & 6.5262 & 5.7224 \\
\hline$-1.4548 * *$ & 0.7038 & & \\
\hline-0.1845 & 0.7664 & 0.5545 & 5.8062 \\
\hline-0.2686 & 0.2225 & $4.5063^{*}$ & 2.3070 \\
\hline-0.0363 & 0.0679 & $-0.9793 *$ & 0.5365 \\
\hline 0.5398 & 0.5140 & -2.8374 & 2.9287 \\
\hline-0.0382 & 0.0557 & 0.6025 & 0.3721 \\
\hline 0.0258 & 0.0293 & 0.3545 & 0.2531 \\
\hline-0.0502 & 0.1389 & 0.3367 & 0.5392 \\
\hline 0.3258 & 0.5350 & $-15.8138^{*}$ & 9.5780 \\
\hline 4.3587 & 10.2548 & $373.5952 * *$ & 166.9091 \\
\hline$-9.3661 *$ & 5.5380 & -24.5465 & 22.1910 \\
\hline $1.1944^{*}$ & 0.7241 & $24.5556^{* * *}$ & 5.2068 \\
\hline 0.9583 & 0.6058 & $10.0106^{*}$ & 5.9136 \\
\hline$-1.4130 * * *$ & 0.2488 & $15.0287 * *$ & 6.2908 \\
\hline 142 & & 91 & \\
\hline 25.66 & & 35.96 & \\
\hline
\end{tabular}

Note: Figures with $* * *$, or $* * *$ are significant at a $10 \%, 5 \%$, or $1 \%$ level, respectively. 

Table 6. Estimation result of data for all units offered by the fixed-effects logit
technique

The middle-stage elderly

The late-stage elderly

Male real estate agents

Young real estate agents

Rents

No. of tatami

Non-RC units

Distance to the nearest station

Age of housing unit

Floor number

Elevators

Ratio of elderly inhabitants in the neighborhood of real estate agents

Ratio of elderly inhabitants in the neighborhood of units

The middle-stage elderly $*$ rents

The late-stage elderly * rents

The middle-stage elderly * age of housing unit

The late-stage elderly * age of housing unit

The middle-stage elderly * ratio of elderly inhabitants in the neighborhood of units

The late-stage elderly * ratio of elderly inhabitants in the neighborhood of units

Differentials of male real estate agents

Differentials of young real estate agents

Constant term

No. of data

$x^{2}$

Notes:

\begin{tabular}{|c|c|c|c|}
\hline \multicolumn{2}{|c|}{ Rental units for singles } & \multicolumn{2}{|c|}{ Rental units for couples } \\
\hline Coefficient & $\begin{array}{c}\text { Standard } \\
\text { error }\end{array}$ & Coefficient & $\begin{array}{c}\text { Standard } \\
\text { error }\end{array}$ \\
\hline-1.0738 & 0.7234 & 2.3335 & 2.1179 \\
\hline$-2.4908 * * *$ & 0.7970 & $4.8186^{* *}$ & 2.1404 \\
\hline-0.2018 & 0.9864 & $-8.4755^{* * *}$ & 3.0228 \\
\hline-0.2178 & 0.7400 & 4.0985 & 10.4355 \\
\hline 0.1224 & 0.4132 & -0.8211 & 0.9759 \\
\hline 0.1215 & 0.0754 & -0.2348 & 0.1588 \\
\hline $1.4366^{* *}$ & 0.5722 & 0.5568 & 0.8649 \\
\hline$-0.1491 * *$ & 0.0725 & -0.1207 & 0.0970 \\
\hline $0.1163 * *$ & 0.0581 & -0.0383 & 0.1331 \\
\hline-0.0692 & 0.1368 & 0.3008 & 0.3144 \\
\hline 0.8228 & 0.5741 & -0.0463 & 1.0472 \\
\hline-25.7850 & 25.7159 & -98.5582 & 68.8461 \\
\hline 5.5523 & 7.6038 & 27.2149 & 40.0643 \\
\hline 0.1712 & 0.5234 & 1.2449 & 0.9095 \\
\hline 0.1283 & 0.4392 & 0.6508 & 1.0894 \\
\hline 0.0805 & 0.0885 & 0.1272 & 0.1597 \\
\hline$-0.1329 *$ & 0.0712 & -0.0101 & 0.1671 \\
\hline$-30.1607 * *$ & 12.5783 & 20.5163 & 41.3727 \\
\hline-10.7418 & 9.7672 & -0.8697 & 44.8130 \\
\hline-1.1154 & 0.8036 & $4.8308^{*}$ & 2.6858 \\
\hline-0.8745 & 0.9655 & 0.9681 & 1.3639 \\
\hline$-0.9986^{* *}$ & 0.4354 & -1.5459 & 1.0443 \\
\hline 178 & & 116 & \\
\hline 52.67 & & 73.73 & \\
\hline
\end{tabular}

1) Figures with $*, * *$, or $* * *$ are significant at a $10 \%, 5 \%$, or $1 \%$ level, respectively.

2) In addition to the variables listed above, a dummy variable for wards and municipalities was used. 
Table 7. Estimation result of real estate agent data using the random-effects probit technique

\begin{tabular}{|c|c|c|c|c|}
\hline & \multicolumn{2}{|c|}{ No. of units available } & \multicolumn{2}{|c|}{ Questions about guarantors } \\
\hline & Coefficient & $\begin{array}{l}\text { Standard } \\
\text { error }\end{array}$ & Coefficient & $\begin{array}{l}\text { Standard } \\
\text { error }\end{array}$ \\
\hline The elderly & $-1.1490 * * *$ & 0.1753 & $1.5191^{* * *}$ & 0.2523 \\
\hline The middle-stage elderly & -0.1399 & 0.2668 & 0.3173 & 0.2918 \\
\hline The late-stage elderly & $-0.6644^{* *}$ & 0.3228 & 0.3087 & 0.3073 \\
\hline Singles & $-1.0733^{* *}$ & 0.5206 & $1.2029^{*}$ & 0.6254 \\
\hline Male real estate agents & $-0.9719 * *$ & 0.4396 & 0.1574 & 0.5541 \\
\hline Young real estate agents & 0.1414 & 0.4409 & -0.4665 & 0.5217 \\
\hline Rents & -0.1817 & 0.1560 & -0.0800 & 0.1814 \\
\hline No. of tatami & -0.0365 & 0.0456 & 0.0745 & 0.0522 \\
\hline Non-RC units & $0.6305^{*}$ & 0.3802 & 0.6280 & 0.4298 \\
\hline Distance to the nearest station & -0.0478 & 0.4081 & -0.0195 & 0.0451 \\
\hline Age of housing unit & 0.0297 & 0.0219 & 0.0299 & 0.0267 \\
\hline Floor number & 0.0281 & 0.0913 & 0.0558 & 0.1000 \\
\hline Elevators & 0.3414 & 0.3825 & -0.2002 & 0.4230 \\
\hline $\begin{array}{l}\text { Ratio of elderly inhabitants in the neighborhood } \\
\text { of real estate agents }\end{array}$ & 0.0850 & 7.3684 & 9.3508 & 8.6889 \\
\hline $\begin{array}{l}\text { Ratio of elderly inhabitants in the neighborhood } \\
\text { of units }\end{array}$ & $-7.5745^{* *}$ & 3.7137 & -3.6248 & 3.8323 \\
\hline Constant term & -1.9674 & 1.2521 & -0.5381 & 1.8275 \\
\hline No. of data & 342 & & 342 & \\
\hline wald $x^{2}$ & 82.33 & & 46.89 & \\
\hline
\end{tabular}

Note: Figures with *, **, or $* * *$ are significant at a $10 \%, 5 \%$, or $1 \%$ level, respectively. 
Table 8. Estimation result of data of all the units offered using the random effect probit technique

\begin{tabular}{|c|c|c|c|c|}
\hline & \multicolumn{2}{|c|}{ Rental units for singles } & \multicolumn{2}{|c|}{ Rental units for couples } \\
\hline & Coefficient & $\begin{array}{l}\text { Standard } \\
\text { error }\end{array}$ & Coefficient & $\begin{array}{l}\text { Standard } \\
\text { error }\end{array}$ \\
\hline The elderly & -0.1689 & 0.1430 & $-1.0419 * * *$ & 0.2028 \\
\hline The middle-stage elderly & $-0.5861 * *$ & 0.2497 & 0.1554 & 0.3107 \\
\hline The late-stage elderly & $-0.4797 * *$ & 0.2261 & 0.3286 & 0.3411 \\
\hline Male real estate agents & -0.3551 & 0.4077 & $-2.2090 * * *$ & 0.5286 \\
\hline Young real estate agents & 0.0908 & 0.3534 & -0.3534 & 0.5343 \\
\hline Rents & 0.0244 & 0.2035 & 0.0499 & 0.1960 \\
\hline No. of tatami & 0.0327 & 0.0394 & -0.0436 & 0.0491 \\
\hline Non-RC units & $0.5755^{* *}$ & 0.2844 & $0.6856^{*}$ & 0.4135 \\
\hline Distance to the nearest station & $-0.0659 *$ & 0.0356 & -0.0612 & 0.0410 \\
\hline Age of housing unit & $0.0545 * *$ & 0.0272 & 0.0206 & 0.0352 \\
\hline Floor number & -0.0237 & 0.0721 & -0.0086 & 0.0805 \\
\hline Elevators & 0.3518 & 0.3214 & 0.0786 & 0.4137 \\
\hline $\begin{array}{l}\text { Ratio of elderly inhabitants in the neighborhood } \\
\text { of real estate agents }\end{array}$ & -10.9176 & 11.4800 & -25.8862 & 17.8443 \\
\hline $\begin{array}{l}\text { Ratio of elderly inhabitants in the neighborhood } \\
\text { of units }\end{array}$ & 2.2095 & 3.7309 & 9.0525 & 5.9827 \\
\hline The middle-stage elderly $*$ rents & -0.1285 & 0.2049 & 0.2524 & 0.1821 \\
\hline The late-stage elderly $*$ rents & -0.0780 & 0.1684 & $-0.4457 * *$ & 0.2203 \\
\hline The middle-stage elderly * age of housing unit & -0.0169 & 0.0313 & 0.0406 & 0.0392 \\
\hline The late-stage elderly * age of housing unit & -0.0364 & 0.0272 & $-0.0772 *$ & 0.0406 \\
\hline $\begin{array}{l}\text { The middle-stage elderly * ratio of elderly } \\
\text { inhabitants in the neighborhood of units }\end{array}$ & $-11.6924 * *$ & 4.8908 & -0.5071 & 6.0871 \\
\hline $\begin{array}{l}\text { The late-stage elderly * ratio of elderly } \\
\text { inhabitants in the neighborhood of units }\end{array}$ & $-7.8324 * *$ & 3.9004 & $15.7213 *$ & 8.2082 \\
\hline Constant term & 1.5062 & 1.6469 & -4.1817 & 2.9926 \\
\hline No. of data & 612 & & 449 & \\
\hline wald $x^{2}$ & 177.11 & & 281.94 & \\
\hline
\end{tabular}

Notes:

1) Figures with $*, * *$, or $* * *$ are significant at a $10 \%, 5 \%$, or $1 \%$ level, respectively.

2) In addition to the variables listed above, a dummy variable for wards and municipalities was used. 
Table 9. Signs of coefficients expected by the six hypotheses and the signs of estimated significant coefficients

\begin{tabular}{|c|c|c|c|c|c|c|c|c|c|c|c|c|c|c|}
\hline & $\mathrm{CH}$ & $\mathrm{DH}$ & $\mathrm{EH}$ & FH & $\mathrm{TH}$ & $\mathrm{RH}$ & $\mathrm{LN}$ & LQ & LS & LC & PN & PQ & PS & PC \\
\hline Singles & - & - & & - & & & - & & & & - & - & & \\
\hline The middle-stage elderly & - & - & & - & + & & & - & & & & & - & \\
\hline The late-stage elderly & - & - & & - & + & & - & - & - & + & - & & - & \\
\hline Male real estate agents & & & & & & - & - & & & - & - & & & - \\
\hline Young real estate agents & & & & & & + & & & & & & & & \\
\hline Rents & & & & - & & & & - & & & & & & \\
\hline No. of tatami & & & & & & & & + & & & & & & \\
\hline Non-RC units & & & & & + & & & & + & & + & & + & + \\
\hline Distance to the nearest station & & & - & & & & & & - & & & & - & \\
\hline Age of housing unit & & & & & + & & & & + & & & & + & \\
\hline Floor number of unit & & & - & & & & & & & & & & & \\
\hline Elevators & & & + & & & & & + & & & & & & \\
\hline $\begin{array}{l}\text { Ratio of elderly inhabitants in the } \\
\text { neighborhood of real estate agents }\end{array}$ & & & & & & + & & - & & & & & & \\
\hline $\begin{array}{l}\text { Ratio of elderly inhabitants in the } \\
\text { neighborhood of units }\end{array}$ & + & - & & & & & - & & & & - & & & \\
\hline The middle-stage elderly $*$ rents & & & & - & & & & & & & & & & \\
\hline The late-stage elderly * rents & & & & - & & & & & & & & & & - \\
\hline $\begin{array}{l}\text { The middle-stage elderly * age of } \\
\text { housing unit }\end{array}$ & & & & & - & & & & & & & & & \\
\hline $\begin{array}{l}\text { The late-stage elderly * age of } \\
\text { housing unit }\end{array}$ & & & & & - & & & & - & & & & & - \\
\hline $\begin{array}{l}\text { The middle-stage elderly * ratio } \\
\text { of elderly inhabitants in the } \\
\text { neighborhood of units }\end{array}$ & + & - & & & & & & & - & & & & - & \\
\hline $\begin{array}{l}\text { The late-stage elderly * ratio of } \\
\text { elderly inhabitants in the } \\
\text { neighborhood of units }\end{array}$ & + & - & & & & & & & & & & & - & + \\
\hline The elderly or constant term & - & - & - & - & - & - & - & - & - & & - & - & & - \\
\hline $\begin{array}{l}\text { Differentials of male real } \\
\text { estate agents }\end{array}$ & & & & & & - & + & - & & + & & & & \\
\hline $\begin{array}{l}\text { Differentials of young real } \\
\text { estate agents }\end{array}$ & & & & & & + & & - & & & & & & \\
\hline
\end{tabular}

1) $\mathrm{CH}$ is the community preference hypothesis, $\mathrm{DH}$ is the disaster prevention hypothesis, $\mathrm{EH}$ is the elderly preference hypothesis,

$\mathrm{FH}$ is future income hypothesis, $\mathrm{TH}$ is the tenancy period hypothesis, and $\mathrm{RH}$ is the real estate agent hypothesis.

2) LN, LQ, LS, and LC are the estimation results for data on the number of units that are available, questions about guarantors, units availability for singles, and units availability for couples, respectively, using the fixed-effects logit technique.

3) PN, PQ, PS, and PC are the estimation results for data on the number of units that are available, questions about guarantors, units availability for singles, and units availability for couples, respectively, using the random-effects probit technique.

4) The estimation results reported in this table are those only for coefficients estimated to be significant at a $10 \%$ level.

5) Because questions about guarantors are negative, the signs shown here are the opposite to the signs actually obtained. 
Table 10. Incidence of discrimination by family structure and age

\begin{tabular}{|l|c|c|c|}
\hline & Units for singles & Units for couples & Total \\
\hline The early-stage elderly & $12.45 \%$ & $24.12 \%$ & $17.18 \%$ \\
\hline The middle-stage elderly & $25.64 \%$ & $18.57 \%$ & $22.57 \%$ \\
\hline The late-stage elderly & $31.51 \%$ & $16.00 \%$ & $24.62 \%$ \\
\hline Total & $22.94 \%$ & $19.33 \%$ & \\
\hline
\end{tabular}

Note: Figures are those obtained by deducting the ratio of units that are only available to elderly home-seekers of all the units real estate agents had in stock from that of units that are only available to young home-seekers only to all the units. 


\section{(References)}

Chamberlain, G. (1980), "Analysis of Covariance with Qualitative Data", The Review of Economic Studies, Vol. 47,pp.225-238.

Nakagawa, M. (2001), "Measuring Age Discrimination in Rental Housing Markets Using a Fair Housing Audit," Urban Housing Sciences, No. 35, pp.21-26 (Japanese).

Nakagawa, M. (2002), "Analysis of Residential Segregation of the Elderly," Urban Housing Sciences, No. 39, pp.19-24 (Japanese).

Ondrich, J., A. Stricker and, J. Yinger (1998),"Do Real Estate Brokers Choose to Discriminate? : Evidence from the 1989 Housing Discrimination Study", Southern Economic Journal 64(4), pp.880-901.

Page, M. (1995), "Racial and Ethnic Discrimination in Urban Housing Markets: Evidence from a Recent Audit Study", Journal of Urban Economics 38, pp.183-206.

Roychoudhury,C. and A. C. Goodman (1992), "An Ordered Probit Model for Racial Discrimination through Fair Housing Audits", Journal of Housing Economics 2, pp.358-373.

Yinger, J. (1986), "Measuring Racial Discrimination with Fair Housing Audits: Caught in the Act", The American Economic Review, Vol.76, No.5, pp.881-893.

Yinger, J. (1991), "Acts of Discrimination: Evidence from the 1989 Housing Discrimination Study", Journal of Housing Economics 1, pp.318-346.

Yinger, J.(1997), "Cash in Your Face: The Cost of Racial and Ethnic Discrimination in Housing", Journal of Urban Economics 42, pp.339-365. 
Notes:

1. There are two checking stages of the tenants in the Japanese rental housing market. The first stage is checking by real estate agents, and the second stage is checking by landlords themselves. Although income was established for each audit, no questions about income were asked by real estate agents in almost all of the audits at the checking stage by real estate agents. Therefore, none of the established income is used in the test of hypotheses reported in the following sections.

2. Where the estimation is concerned with the number of units that are available and whether particular questions were asked or not, for each real estate agent, the explained variable is $A_{i}{ }^{a}$, and $Y_{i j}{ }^{a}$ is excluded from the explanatory variable.

3. No comparison between the two fair housing audits is possible for "questions about occupation" and "questions about income" because the audits' data collection method differed.

4. The result of $\mathrm{R}^{2}$ reported here is that obtained by the ordinary least squares (OLS) using a dummy variable for real estate agents.

5. Moreover, the landlords in a community of young inhabitants are not very experienced in the management of elderly tenants, and so may be unable to take proper action if these tenants suffer from any changes in physical condition.

6. The author tried to obtain information on barrier-free houses (houses with specifications and facilities devised for the elderly), but was unable to obtain the information for almost all the houses surveyed.

7. The design of the 2002 Osaka Audits was based on the premise that the young auditors were public employees working at Osaka University and the elderly auditors were pensioners. If the rent of the unit was very high, the elderly auditor was assumed to own a rental unit in another area and have a stable income in addition to his pension. Thus, the risk of dismissal was excluded, and the design adopted only the risk of increasing expenses due to changes in physical condition.

8. The Japanese Tenant Protection Law prohibits a landlord from ejecting a tenant from the house, except in special cases, such as if the tenant fails to pay rent. Also, if the tenant refuses a rent rise, the landlord cannot increase the rent unless he or she obtains permission from a court.

9. According to the "Report of the Basic Statistical Survey on Wage Structure 2001" (Ministry of Health, Labour and Welfare), the ratio of workers who continued to work for 15 years or more at a firm with $10-99$ employees was $27 \%$ for males and $17 \%$ for females. 
10. The data on advertised units are used here. Because the number of samples is limited, the dummy variable for wards and municipalities, and the cross terms of the age of elderly home-seekers and "rents," "age of housing unit," and "ratio of elderly inhabitants in the neighborhood of units," which are used in the estimations shown in Tables 6 and 8 below, are not used in the estimation shown in Tables 5 and 7.

11. Significant coefficients were estimated for the "ratio of elderly inhabitants in the neighborhood of real estate agents" and "differentials of young real estate agents," too, but their relations with the hypotheses are not very clear.

12. In 2000, the fixed term house lease system, under which a house lease contract expires after a certain period, was created. 